O presente artigo intenta compreender o conceito de obra literária nos textos de Roman Ingarden a partir das noções de artefato e performance, isto é, a obra de arte como uma artificialização e virtualização do real, segundo uma intencionalidade que configura o sentido como um modo de agir ou uma instrução para ação. Para tal, torna-se necessário localizar a filosofia da arte de Ingarden, distanciada de uma filosofia estética e em consonância, a partir dos anos 1960, com a filosofia da arte anglófona, sobretudo no que concerne ao seu foco ontológico e contextualista.

PALAVRAS-ChaVE: ontologia, artefato, performance, Roman Ingarden.

\title{
INTRODUÇÃO
}

O presente artigo intenta apresentar uma interpretação distinta de outras, mais costumeiras, da obra de Roman Ingarden ao compreender o conceito de obra literária nos textos do autor polonês a partir das noções de artefato e performance, isto é, ao propor pensar a obra de arte como uma artificialização e virtualização do real segundo uma intencionalidade que configura o sentido como um modo de agir ou uma instrução para ação. Para tal, torna-se necessário localizar a filosofia da arte de Ingarden distanciada de uma filosofia estética e em consonância, a partir dos anos 1960, com a filosofia da arte anglófona, o que será feito com base em Amie Thomasson (1999), no que concerne a uma ontologia da obra de arte literária, em proximidade com a obra John

* Professor no Instituto de Letras e Comunicação da Universidade Federal do Pará (UFPA), Belem, Pará, Brasil. Doutorado em Literatura pela Universidade Federal de Santa Catarina (UFSC), Florianópolis, Santa Catarina, Brasil. E-mail: nonada1@gmail.com. 
Searle (1997), por uma base ontológica contextualista, entre diversos outros autores que, se não retomam o autor polonês diretamente, compartilham com ele um modo de pensar o modo de ser da obra de literária e, mais importante, reavaliam as construções conceituais de Ingarden.

\section{DiSTINÇÃO ARTÍSTICO/ESTÉTICO}

A obra de arte literária, a partir da ontologia proposta em The Literary work of art de Roman Ingarden (1973a), originalmente publicada em 1931, é entendida como uma construção esquemática em que os elementos existem em estado de potencialidade. Ela é distinta das suas concretizações, pois estas são atualizações contingentes, sempre parciais e diferentes, dentro de uma gama de possibilidades estabelecida com a formação potencial dos estratos. Nunca há uma atualização total e completa das potencialidades da obra de arte. Várias leituras da mesma obra, realizadas pelo mesmo indivíduo, renderão várias concretizações diferentes da mesma obra de arte. $\mathrm{O}$ que assegura uma identidade das concretizações é sua execução como ato intencional a partir de um mesmo objeto esquemático, a obra de arte. E é somente com a concretização que chegamos a um objeto estético que, como a concretização, é contingente e distinto, podendo, portanto, uma mesma obra render diversos objetos estéticos.

Assim, ao longo do desenrolar de sua obra, Ingarden (1973b, 1961, 1964) continuamente distingue e precisa essa concepção em três momentos ontológicos: 1) o objeto real físico (livro impresso composto de tinta, papel, sons sendo proferidos etc.); 2) a obra de arte (construção esquemática); 3) a concretização (que pode ou não levar a um objeto estético).

Essa distinção é uma chave fundamental para compreender toda análise empreendida por Ingarden, tanto da obra de arte quanto do modo de existência das entidades intencionais. Nela, uma entidade leva à outra, porém, todas são distintas e devem ser explicitamente diferenciadas. Isso se torna evidente em termos de suas respectivas qualidades de valor, havendo um tipo de valor associado a cada momento, ou seja, entre as qualidades de valor artístico e as qualidades de valor estético, 
o que é explicitado em sua conferência Artistic and Aesthetic Values (1964), apresentada para o British Society of Aesthetics em 1963, três anos após a fundação da mesma, e publicada em 1964. Nela, ele resume da seguinte forma o que acaba de ser dito:

Artistic value [...] is something which arises in the work of art itself
and has its existential ground in that. Aesthetic value is something
which manifests itself only in the aesthetic object and as a particular
moment which determines the character of the whole. The ground
of aesthetic value consists of a certain aggregation of aesthetically
valuable qualities, and they in turn rest upon the basis of a certain
aggregate of properties which render possible their emergence in an
object. Both the one and the other kind of value assume the exis-
tence of a complete work of art (or aesthetic object). (INGARDEN,
1964, p. 205, grifo do autor).

As qualidades artísticas não são propriedades dependentes do respondente, para usar a termologia do filósofo norte-americano Noël Carroll (2003), mas as qualidades de valor estético o são. Na concepção de Ingarden (1964) não existe na obra de arte um valor puramente subjetivo (pura afecção), pelo simples fato de que um valor completamente subjetivo - conforme seria em filosofias estéticas como as de Kant (1987), Schiller (1995) ou Greenberg (2000) - não teria relação com a obra de arte e, logo, não derivaria desta. É precisamente o que afirma Carroll (2003) quando indica que na análise estética havia uma indiferença existencial radical, em que não havia interesse pela existência ou não do objeto. Ao mesmo tempo, Graham Mcfee (2011) defende que não há percepção pura porque toda relação de qualidade é sempre parte de uma apreensão contextual localizada e é constituída aí. O juízo artístico é sempre o juízo de uma obra de arte. ${ }^{2}$ Isso significa que a afecção derivada da arte está localizada como derivada do objeto artístico e, por essa razão, não é a mesma coisa que o prazer ou desprazer derivado de uma paisagem natural, de estar bem alimentado após um bom almoço ou de ter tomado um banho ou respirar ar fresco. Ingarden (1964) aponta para essa compreensão, quando afirma que não existe valor inteiramente independente do contexto. Uma afecção não contextual não diria nada do objeto em questão. Logo, há um grau em que a própria noção de valor estético em Ingarden é subserviente tanto 
a elementos histórico-contextuais quanto a apreensão total da obra, não podendo ser resumida à afecção subjetiva. Fato que se torna mais evidente quando marcado em seu professo foco por uma ontologia em detrimento à base epistemológica idealista-transcendental de Husserl (INGARDEN, 1975b).

Diante, então, dos três momentos acima citados - objeto real físico, obra de arte e concretização (e objeto estético) - temos uma relação de valor, explicitada a seguir. Ora, o objeto físico porta apenas propriedades físicas, axiologicamente neutras, de valor. Estas são atributos como, por exemplo, os estratos, sua formatação temporal, estrutura formal, que respondem, sobretudo, às perguntas "o que é" ou "o que há" materialmente. Elas formam o que Ingarden (1964) chama de esqueleto axiologicamente neutro da obra de arte e é a partir delas que emergem as qualidades artísticas axiologicamente significantes.

A obra de arte possui tanto propriedades axiologicamente neutras - como tendo certo tipo de estrutura de frase, sendo composto com um léxico característico de uma região X ou Y, repetição de tais elementos, ou estando composto com certo tipo de verso ${ }^{3}$ quanto qualidades de valor artístico (negativo ou positivo) fundadas nessas qualidades neutras - como clareza ou obscuridade de expressão, domínio técnico no trabalho dos versos, brevidade, ordenação, desordenação etc. Acerca das qualidades artísticas, Ingarden estabelece o seguinte:

1. It is neither a part nor an aspect of any of our empirical experiences or mental states during commerce with a work of art and therefore does not belong to the category of pleasure or enjoyment.

2. It is not something attributed to the work in virtue of being regarded as an instrument for arousing this or that form of pleasure.

3. It reveals itself as a specific characteristic of the work itself.

4. It exists if and only if the necessary conditions for its existence are present in the qualities of the work itself.

5. It is such a thing that its presence causes the work of art to partake of an entirely special form of being distinct from all other cultural products. (INGARDEN, 1964, p. 201). ${ }^{4}$ 
O que importa notar aqui é que estes são "fatos brutos". Eles são referentes, principalmente, ao fazer artístico, baseados em um domínio e capacidade técnica e, como tal, o valor artístico se dá com base na maneira como os elementos estão arranjados/ configurados/ formados dentro de um todo emergente da obra de arte, isto é, ele só pode ser determinado com relação ao seu lugar, dentro desse todo e de seu entorno:

In this connection, in order to discover whether a certain aspect of a work has positive or negative value it is not enough to examine the value characteristics of that aspect in isolation; it is necessary to extend one's survey to the whole work, since various qualities of this kind may, and sometimes must, exercise a mutual influence on each other in regard to their value characteristics and it is only in the whole organic unity of the work (where both its neutral and its value significant features are taken into account) that their final form is revealed. This is in agreement with the earlier statement that the real function of artistically valuable moments is revealed only on the basis of an appreciation of the work, which is not possible so long as we confine ourselves to the enjoyment of these or the other empirical pleasures mediated by it. (INGARDEN, 1964, p. 210). ${ }^{5}$

Sendo assim, o valor artístico dos atributos surge com relação à totalidade da obra e a sua função, objetivos e intenções como tal. Isso implica uma forte relação contextual e a possibilidade de medir o sucesso de uma empreita artística. Nada adianta o autor ter a intenção de escrever um poema encomiástico se compõe versos que não deixam claro essa intenção de elogio. Um exemplo usado por Ingarden é o fato de que as esculturas de mármore de Rodin conseguem representar a pele humana. Trata-se de uma função artística - produzida por meios técnicos - de usar material para representar outro. O que Ingarden deseja deixar claro é que o atributo de valor artístico não é relativo ao observador, ele é: "something detectable in the work itself and not to be identified with any subjective experience or psychological state of admiration or pleasure" (INGARDEN, 1964, p. 210), isto é, não dependem da afecção subjetiva, não há afecção nos atributos de valor artístico, ele é ligado a um fazer, à obra de arte. 
Distintamente, os valores estéticos, nomeados por Ingarden, como serenidade, sublimidade, profundidade, tristeza, inteligência, elegância, simplicidade, uniformidade etc. só se manifestam no objeto estético, trazido à tona, através da concretização da obra de arte que tenha sido empreendida em uma atitude estética. Como já indicado, são valores que subentendem a participação do sujeito na sua formação. Mas, diferentemente do valor estético de uma concepção puramente estética da arte (como a kantiana), Ingarden funda esta recepção na concretização a partir da obra de arte, o que implica tanto a pertinência de atributos artísticos quanto de elementos contextuais, de modo que não há uma pura afecção subjetiva. Ora, para que as qualidades de valor estético surjam daí é necessária uma atitude já estética com relação à obra de arte. Dentre os tipos de valor que Ingarden tem em mente, estes têm uma diversidade até mesmo estranha, já que ele agrupa coisas distintas como valores: emocionais, intelectuais, formais e uma categoria não nomeada pertinente à artificialidade/ naturalidade, genuinidade/ falsidade etc. O que deve ser notado é que os valores estéticos caracterizam o objeto estético como uma totalidade e não como elementos isolados, mesmo tendo sua origem a partir de diversas propriedades particulares da obra de arte e do objeto físico, apesar de ser dependente destes (INGARDEN, 1964; THOMASSON, 2012).

O que também deve ficar marcado é que Ingarden poderia ser visto como um contextualista, já que nada tem propriamente valor por si. Até a valoração "estética" da obra de arte parte e depende de elementos socioculturais. Isso se deve a uma coerência óbvia de ter a obra de arte literária como uma entidade intencional. Uma entidade que é constituída por atos de intencionalidade depende de reconhecimento e concretizações contingentes e mundanas para serem/ existirem. Após negar o subjetivismo, não é possível, então, retomar qualquer ideia de valor intrínseco ou puramente subjetivo universal-desinteressado da obra, como fazia a análise estética.

Há aqui, na relação objeto real, obra de arte, concretização (objeto estético), uma relação ontológica de dependência hierárquica, em que temos três fases que não podem ser desassociadas. Ou seja, as qualidades estéticas não podem ser desligadas, nem ôntica nem fenomenalmente, dos seus fundamentos constitutivos na concretização a partir da obra de arte, nem a obra de arte pode ser desligada de seus 
fundamentos reais (INGARDEN, 1973a). Refletindo a base ontológica realista formal de Ingarden, o fundamento para toda análise posterior de valor sobre o real tem início no axiologicamente neutro. Este é a base da configuração esquemática da obra de arte. Em consequência disso, a obra de arte é anterior ao objeto estético, isto é, o objeto estético é algo posterior ao ato de concretização (ele só surge com a concretização), somente no estágio final desse movimento artístico. Assim, pode-se dizer que o que importa para se caracterizar o ser-arte é a configuração esquemática e sua concretização (basta lembrar o quinto ponto das condições necessárias para o valor artístico acima citado, e ter claro que ela se refere a uma diferença cultural). A partir daí o objeto estético pode se dar ou não. Fica claro que, para Ingarden, ele deveria se dar, mas não é algo que necessariamente irá acontecer (não pode ser apontado como condição necessária).

Assim, para Ingarden (1964), aquele que irá apreender a obra de arte se coloca em uma atitude estética, que o permite ter uma experiência estética e construir um objeto estético, perceber qualidades de valor estético e, por fim, chegar a um valor estético. Ou seja, sua fundamentação para explicar o surgimento de um valor estético ainda está próximo das concepções modernas que garantiam uma recepção estética por meio de uma atitude estética. Ele ainda submete a obra de arte a uma realização estética. Entretanto, essa realização é distinta das noções como as de Kant (1987), Schiller (1995) e Greenberg (2000), visto que Ingarden (1975a), já em sua recusa ao psicologismo, recusa, explicitamente, cair em um subjetivismo. Apesar de Ingarden submeter a obra de arte a uma realização estética, esta, dentro de sua formulação teórica operando metodologicamente em uma ontologia realista, tem muito pouca força e não pode ser a base para sustentar o ser-arte (não é fundante do ser-arte). $\mathrm{O}$ objeto estético está de tal maneira situado ao final de uma hierarquia ontológica que ele poderia ser retirado de sua posição, sem prejudicar as formulações acerca da intencionalidade, da configuração esquemática e da concretização (as teses centrais de Ingarden). Isto é consequência de uma filosofia que se debruça formalmente sobre o objeto artístico em sua particularidade ontológica, admitindo certo grau de autonomia deste com relação ao sujeito, ou seja, tendo a obra de arte como um artefato/ construto e não meramente como uma afecção. 
A possibilidade não estética se torna mais aparente quando Ingarden (1973a, 1964) salienta a possibilidade de outras concretizações que não engendram um objeto estético ao final. Pode-se, por exemplo, ler a obra de arte para adquirir informações concernentes a um período histórico ou para descobrir certos comportamentos sociais de um dado conjunto de pessoas. Em ambos os casos há a concretização da obra de arte, sem que esta acabe em um objeto estético. O detalhe é que essa concretização não estética não faz a coisa deixar de ser arte, ou, inversamente, não é a concretização de um objeto estético que faz algo ser arte. A implicação que tento desprender disso é que a obra de arte literária pode ser plenamente apreendida sem necessitar de uma apreensão estética, ou que, simplesmente, ela não seja o ponto principal da obra de arte.

O ano da publicação de Artistic and Aesthetic Values (1964), no British Journal of Aesthetics, é marcado ainda pela publicação, em periódicos diferentes, de dois outros artigos basilares para a filosofia da arte anglófona. Estes são The Artworld, de Arthur Danto (1964), e o The Myth of the Aesthetic Attitude, de George Dickie (1964). Tais artigos marcam a tendência anglófona de recusar não apenas a análise estética, como faz Ingarden, mas de pensar a arte sem necessidade de uma qualificação estética, como fundamental ao ser-arte. Isso se dá em Danto, quando ele propõe um modelo que compreende o reconhecimento de algo como arte por seu lugar dentro de um contexto teórico. E, em Dickie, pela crítica a um "misticismo" ou vagueza constante nas diversas formulações dos conceitos de "atitude estética" ou "percepção estética". Consequentemente, se lermos o artigo de Ingarden cotejando-o com o de Danto e de Dickie, é possível compreendê-lo como ainda apegado a certos elementos de uma análise estética (como "atitude estética" ou "experiência estética"), sem, no entanto, dar um peso central a elas, recusando, diretamente, os modelos de análise estética e, ainda, indicando outro tipo de valor possível, qual seja, o valor artístico. Destarte, sugiro que é possível ler a filosofia de Ingarden apropriando a sua formulação ontológica realista e o sistema de concretização, recusando o que ainda havia nele de uma análise estética. 
Uma vez colocadas todas as distinções acima, devemos notar que Ingarden estabelece quatro bases ônticas da obra de arte, necessárias para sua plena existência: 1) operações subjetivas de consciência de quem produz e de quem experiencia; 2) operações objetivas de quem produz e de quem experiencia (atos motores, práticas etc.); 3) conceitos e sentidos intersubjetivos pelos quais a consciência confere e apreende significações; finalmente; 4) o material, real objetivo (gráfico, sonoro etc.), essencial para o suporte (texto escrita, tinta, disco, computador etc.) (INGARDEN, 1973a; MITSCHERLING, 1997; FERREIRA, 2010). A obra não se reduz a estes elementos, mas também não existe sem eles. Ela é uma totalidade emergente a partir destes. Porém, para entender o estatuto ontológico da obra de arte, é necessário retomar o problema inicial de entidades reais, ideais e intencionais, especificamente com relação ao elemento intersubjetivo da linguagem, quando Ingarden declara que:

My findings agree with Husserl's view, expressed in his Formal and Transcendental Logic, that word meanings, sentences, and higher units of meaning are formations which arise from subjective conscious operations. Thus they are not ideal objectivities in the sense in which Husserl himself determined them in his Logical Investigations. But while Husserl keeps the term "ideal" in most instances in his Logic and only at times adds the word "unreal" [irreal] in parentheses, I have totally abandoned this term and seek sharply to counterpose these formations to ideal objectivities in the strict sense. This is the first essential difference; all objectivities which he previously held to be ideal - in the old sense - Husserl now considers to be intentional formations of a particular kind, and in this way he arrives at a universal extension of transcendental idealism; whereas I today still maintain the strict ideality of various ideal objectivities (ideal concepts, ideal individual objects, ideas and essences) and indeed see in ideal concepts an ontic foundation of word meanings that enables them to have intersubjective identity and an ontically autonomous mode of existence. At the same time, for Husserl the new conception of logical formations springs primarily from phenomenological investigations and general transcendental-idealistic motives, whereas my observations are ontologically oriented and 
seek to show, in the logical formations themselves, a series of states of affairs which make ideal existence in the strict sense impossible for them and which simultaneously indicate their ontic origin in subjective operations. (INGARDEN, 1973a, p. lxxiv, grifo meu). ${ }^{7}$

Fica claro que a noção de construto é central para concepção de obra de arte de Ingarden. Apesar de fundar a obra - via significação tanto em elementos ideais quanto reais, a obra, como entidade intencional pura, é fruto de ações subjetivas concretas (que não devem ser entendidas aqui como psicologismo subjetivista, mas sim comportando desde reconhecimento social de um fato cultural até mesmo atos físicos). Isso quer dizer que ela é construída como um artefato intencional. Qualquer elaboração mental, "ideia" ou concepção da obra é uma construção subjetiva fruto de um ato intencional do autor. Assim, a "essência" de uma obra é sempre um construto limitado espaço temporalmente. Os elementos ideais da significação não são parte da obra, mas elementos externos autônomos que jamais podem ser criados (não tem existência espaço temporal, não é criado, nem pode ser destruído), sendo possível somente ligar estes ideais ao fônico real. ${ }^{8}$ Todavia, se a significação está relacionada ao ideal, com a palavra, vale notar que Ingarden, tem a unidade de significação mínima como a frase (em oposição a Husserl, que a localiza na palavra), ou seja, a significação mínima da obra de arte literária está situada numa construção, em um conjunto contingente que, apesar de ser fundado sobre significações que envolvem ideais, não se limita a eles nem pode ser reduzido somente a eles. É preciso sempre levar em conta o ato de composição - configurar e construir do objeto literário.

Além disso, se a importância do ideal está nessa existência como elemento intersubjetivo que elimina o psicologismo, é plenamente possível substituí-lo por uma concepção em que uma palavra significa algo para mim e de outra forma para outrem porque assim fomos levados a compreender dentro de um uso comum consensual institucional. Embora Ingarden tenha sido formado em uma concepção de análise lógico-semântica da linguagem (como Edmund Husserl, Gottlob Frege e vários outros, sob a denominação de analíticos) ${ }^{9}$, considerando-a como representação e conhecimento e pressupondo uma independência da forma lógica com relação aos interlocutores, ao contexto e à linguagem 
usada (BRAIDA, 2013), ele propõe um outro modelo de linguagem que, se não precisamente dentro do modelo intencional pragmático, como John L. Austin (1999) e John R. Searle (1984), tem certo grau de proximidade com esta ao pressupor a importância contextual ampla e da linguagem como tendo um caráter também acional performativo (i.e., que propõe uma ação, que, no caso específico da obra de arte literária, se daria na concretização). Pode-se observar o que foi dito: 1) na sua constante referência à possibilidade de a obra de arte literária afetar o leitor/ público através dos modos de construir/ configurar e articular a linguagem, especialmente, mas não exclusivamente, pelos estratos de formações fônico-linguísticas e unidades de significação; ${ }^{10}$ 2) indiretamente, em sua formulação do caráter "quase judicativo" da obra de arte literária (cf. $\$ 25$ da Literary Work of Art), ao retirar a necessidade de uma asserção de valor de verdade como condição necessária para que haja significação. ${ }^{11} \mathrm{Ou}$ seja, se levarmos em conta o fato que, no $\S 66$ da Literary Work of Art (1973a), Ingarden apresenta os conceitos ideais como uma "hipótese" (1973a, p. 364) que está presente para eliminar o perigo de se cair num psicologismo (em que cada leitura seria um objeto independente), e lembramos que a proposta original de Ingarden é de que a formulação da Literary Work of Art (1973a) seja base para futuras elaborações teóricas acerca da obra de arte literária, então, é possível e válido eliminarmos completamente os conceitos ideais (qualquer universal) por meio de uma compreensão institucional contextual e consensual que assim mantém o elemento intersubjetivo, caro a Ingarden.

Se na dupla articulação de Ingarden entre ideal e real estabelecermos, portanto, que os ideais são construções intencionais contextuais e consensuais (aceitos por um conjunto de pessoas) como fatos sociais - fatos envolvendo uma intencionalidade coletiva para existir - conforme John R. Searle (1997), isto é, como uma série de reconhecimentos e práticas com relação à maneira de fazermos coisas e agirmos em sociedade, poderemos pensar a obra de arte, seguindo a leitura de Amie Thomasson (1999), como um artefato abstrato, um tipo de abstracta dependente, tendo abstracta como:

as those entities that are not rigidly constantly dependent on any real entity and so lack a spatiotemporal location. This conception is 
close to the most common understanding of the term "abstract" and makes concreta and abstracta mutually exclusive and exhaustive categories. (THOMASSON, 1999, p. 127). ${ }^{12}$

Isto é, similar a coisas como leis, teorias, instituições, conceitos, personagens, proposições, e uma séria de entidades culturais elaboradas através de atos intencionais, ao mesmo tempo, similar a programas de computador ou entidades que comportam múltiplas instanciações. $\mathrm{Ou}$ seja, estes são similares a artefatos físicos construídos - no sentido de que são feitos e podem ser destruídos -, que necessitam de alguma base real/ material espaço-temporalmente localizada e determinada de entidades contingentes - como livros, textos, pessoas -, mas que são abstratos pelo fato de não terem localização espaço-temporal precisa:

unlike the Platonist's abstracta, works of music and literature do not exist independently; they can only come into existence through forms of human intentionality, and even once created, they are not independent and eternal, but depend for their ongoing existence on that of some copy or performance, or the means for creating one (whether via a score, recording, memory, or some combination of these) (THOMASSON, 2004, p. 90, grifos da autora). ${ }^{13}$

Fazendo o movimento inverso, pode-se dizer que os artefatos não artísticos que temos diante nós são mais do que o mero real. Eles são realidades ou fatos brutos artificializados por uma intencionalidade, sendo assim artefatos culturais. ${ }^{14}$ Todos eles dependem, em certo grau, de um ato e reconhecimento intencional para existirem como tal:

For, like paintings and sculptures, other artifacts and concrete social objects such as tables, drivers' licenses, and pieces of real estate are not merely identical with the matter that constitutes them, since they (unlike the matter) have essential relations to human intentional states. Like works of music and literature, theories, corporations and laws of state seem to be abstract cultural entities that are created at a certain time through human activities. (THOMASSON, 2004, p. 90). ${ }^{15}$

Ser fruto da intencionalidade humana implica ser feito e ser cultural. Implica ter características que um fato bruto como uma pedra ou terra não necessitam ter para serem pedra ou terra. Diferente destes, 
a obra de arte necessita de algo a mais para ser arte (e não algo natural). A recusa de Ingarden (1973a, 1964) em igualar arte ao objeto real ou à afecção subjetiva é congênere à distinção entre artístico e estético, elaborada por filósofos contemporâneos como Danto (1981), Mcfee (2011), Carroll (2003), Dickie (1964), Margolis (1977) e Thomasson (2004), isto é, tanto para Ingarden quanto para estes a obra de arte tem características e atribuições que não podem ser identificadas ou atribuídas a um mero fato bruto, a algo natural, ou a um mero "estético". A obra de arte como um artefato é um construto intencional cultural e, isso, como bem aponta Margolis, implica ter características que o objeto real não tem:

works of art are the products of culturally informed labor and that physical objects are not. So seen, they must possess properties that physical objects, qua physical objects, do not and cannot possess. (MARGOLIS, 1977, p. 48). ${ }^{16}$

Sendo assim, existe uma vinculação entre a distinção ontológica objeto real e obra de arte, em que ser obra de arte é ser um artefato e artifício.

Hamlet, Prince of Denmark de William Shakespeare (2003), por exemplo, de forma intencional pragmática, pode ser compreendido como um artefato abstrato, como também o pode o personagem Hamlet. Estes não seriam, então, meramente enunciados lógicos que teriam o propósito de representar algo mentalmente (fundado sobre uma idealidade e independência do contexto do que é dito). O personagem Hamlet é um construto intencional, um esquema para realização/ construção de um "Hamlet" possível e sempre distinto, da mesma forma que a peça (texto) como um todo é um esquema potencial, uma instrução, para a concretização/ construção da obra Hamlet, Prince of Denmark. $\mathrm{O}$ que vale tanto para um romance, poema ou peça teatral. Todos são instruções para uma concretização/ ação. A "essência" do personagem Hamlet foi construída por Shakespeare como instruções. Elas são um modo de artificializar o sentir/ perceber/ dizer/ agir "Hamlet". No caso do teatro elas são instruções para "ser" Hamlet em ato/ performance. Se ajo como proposto, pareio meu modo de ser ao da obra de arte e artificializo-me com relação ao seu modo de operar. E essa instrução, 
como esquema, é incompleta, o que quer dizer que há uma indicação para um modo de ser da concretização aberto o suficiente para que haja diferenciações nas execuções, porém, não completamente arbitrário. A obra de arte então não é o livro-coisa-real, composto de papel e signos gráficos, nem uma ideia atemporal autônoma, mas uma configuração, um esquema potencial para ação-artifício, um "disponível para ação", um "pronto para", um virtual.

\section{ViRTUAL/ PotenCIAL}

Fenomenologicamente, a identidade não é dada na coisa física. Apesar da integridade do objeto real, sempre apreendemos por facetas ou aspectos de uma coisa. Nunca temos a coisa em si completa e absoluta (SOKOLOWSKI, 1999). Nunca vejo simultaneamente todas as faces de um cubo, mas o constituo como uma totalidade. ${ }^{17} \mathrm{Eu}$ o intenciono como totalidade, como um sentido para apreendê-lo, isto é, apreender algo é intencionar como sentido, dar sentido (um construto a partir do real). Apreender o sentido - intencionar e compô-lo - é também apreender e compreender o físico, a materialidade. A obra de arte literária é uma intencionalidade derivada, sua execução vem de uma intencionalidade a partir de uma base material, ou como Thomasson esclarece, a intencionalidade derivada é:

a representational ability derived from intentional acts that confer meaning on phonetic (and typographic) formations. Thus, although fictional characters remain mediately dependent on intentionality, the immediate dependence of fictional characters on words and sentences gives them a relative independence from any particular act of consciousness. (THOMASSON, 1999, p. 22). ${ }^{18}$

O que Thomasson (1999) diz sobre personagens vale para a obra de arte como um todo e implica tanto um grau de autonomia do construto (como materialidade que pode "existir" sem estar sendo atualizado) quanto que a obra de arte se refere ao material/ real na apreensão e uma vez apreendida. Quer dizer que a apreensão de um sentido altera, constantemente, reatualiza nosso modo de ter a coisa física tanto no grau de um leitor quanto com relação a uma comunidade inteira de leitores. 
Com a distinção entre: 1) objeto real/ fisical; 2) obra de arte; e 3) concretização e o fato de que a obra de arte não é o objeto real, nem algum ideal (menos ainda uma afecção subjetiva), mas um objeto intencional, devemos entender - a partir dos artigos de Ingarden Aesthetic experience and aesthetic object $(1961)^{19}$ e Phenomenological aesthetics: an attempt at defining its range (1975a $)^{20}$ - sua noção de que o artista virtualiza/ potencializa um objeto real para produzir uma obra de arte. O real, assim, é o fundo e a fundação sobre a qual a obra de arte aparece, isto é: "The material world enters as a background and displays itself in the shape of the ontological foundation of the work of art" (1975a, p. 260). ${ }^{21}$ Direi ainda que o ato de virtualizar e de potencializar é também um ato de artificializar.

Um poema seria uma série de reais (grafemas ou sons) virtualizados/ potencializados para serem concretizados/atualizados por um leitor durante a leitura ou recitação. Até mesmo em uma escultura, sua base material/ real não é a obra de arte. É a partir da base material que há uma obra - artefato abstrato - que será concretizada. A partir de um real, nós concretizamos aspectos esquematizados da estátua (de forma que essa atualização será sempre distinta). E por ser de uma intencionalidade derivada, essa concretização irá referir de volta ao objeto material, levando daí a constantes mudanças histórico-culturais de como vemos a mesma obra de arte através de diferentes tradições de concretização (INGARDEN, 1973a, 1961).22

Esse ato de virtualização/ potencialização como ato inventivo em Ingarden permite que qualquer coisa, evento, estado, seja construído/ artificializado como uma obra de arte por alguém:

This object, thing, process, or event may be something purely physical, or a certain fact in the life, and experience of the observer, or a musical motif, a snatch of a melody, or a harmony of sounds, a color contrast, or a particular metaphysical quality. (INGARDEN, 1975a, p. 263). ${ }^{23}$

Podemos dizer que o artista artificializa algo, que o retira do natural, potencializando-o para uma concretização:

the creative behavior of an artist covers not only his productive experiences, but also certain physical actions which suitably shape a 
particular thing or process, so that it can perform the function of an ontological basis of a painting, a sculpture, a poem, or a sonata. (INGARDEN, 1975a, p. 260). ${ }^{24}$

$\mathrm{O}$ artista, com efeito, produz um artefato abstrato a partir do real. O real moldado, ou dir-se-ia virtualizado/ artificializado, é o pano de fundo a partir do qual a obra de arte pode aparecer (INGARDEN, 1975a). Assim, lembrando um pouco a proposta do filosofo norte-americano John Searle (1997), de que uma intencionalidade coletiva pode instituir e reconhecer um fato bruto $\mathrm{X}$ como uma entidade cultural $\mathrm{Y}$ no contexto $\mathrm{C}$, podemos dizer que Ingarden propõe um sistema no qual um objeto $\mathrm{X}$ (fato bruto), através de certo procedimento, seja considerado como uma obra de arte $\mathrm{Y}$ (fato institucional-intencional), na situação $\mathrm{C}$, de modo que o objeto real possa, por um ato/ procedimento normatizado concretizar algo que reconhecemos como arte. Isso significa que, através da proposta de Ingarden, coisas distintas como um readymade, uma máscara religiosa africana, textos recortados de jornais ou um tronco morto que acabe na praia possam ser plenamente compreendidos como obra de arte, da mesma forma que seria um poema ou uma pintura. De acordo com a teoria de John Searle (1997), o que importa para essa virtualização do real são os atos intencionais que instituem e reconhecem um $\mathrm{X}$ como $\mathrm{Y}$ em $\mathrm{C}$, isto é, práticas e hábitos sociais que reconhecem um fato bruto (um monte de pedra esculpida e um urinol) como uma obra de arte (uma escultura como a Vênus de Milo e um readymade como a Fonte de Duchamp) e, portanto, atribuímos a eles características e interpretações que não seriam válidas para o objeto real (não arte). Como já foi visto em Margolis (1977) acima, mas também afirmado por Danto (1981), Mcfee (2011), Carroll (2003) e Thomasson (1999) a obra de arte possui propriedade que um fato bruto não pode possuir. Por exemplo, à Fonte de Duchamp podemos atribuir ligações com a história da escultura - certos padrões ou retomadas -, podemos atribuir um caráter irreverente ou falar de suas implicações na representação da masculinidade na sociedade atual. Tais não poderiam ser atribuídas a um mictório em um banheiro sem incorrer em falácia ou erro. Não se trata, portanto, de forma alguma de um ser-arte fundado no gosto subjetivo de um indivíduo (no sentido de "isso é arte para mim"), mas de um fato intencional e institucional que está fundado, sobretudo, 
em atos e práticas no mundo fático. ${ }^{25}$ Assim, é possível compreender o artifício, o ato de artificializar, como uma virtualização do real.

A implicação direta disso é que o real, em seu caráter sensórioperceptivo, não dá conta de dizer se algo é arte. A filosofia da arte de Ingarden chega assim a uma constatação próxima àquela de Arthur Danto, quando este afirma que "To see something as art requires something the eye cannot descry" (1964, p. 580). ${ }^{26}$ Se no caso de Danto a resposta a esse problema envereda por um sentido construído a partir de uma teoria da arte, no caso de Ingarden, a resposta trilha pela virtualização/ artificialização do real via a intencionalidade que é efetivada no ato da concretização.

\section{SENTIDO CONSTRUÍDO COMO INDICAÇão PARA AÇÃO}

Tendo isso em mente, vale entender que "essência" ou "sentido" da obra são construtos, são os esquemas/instruções para a concretização/ realização/ construção da obra de arte. Concretizar a obra é apreender seu sentido. Não há como apreendê-lo sem executá-lo, pois executar e apreender são a mesma coisa. Apreender o sentido é apreender também um modo de funcionar da obra, é executá-la. Da mesma forma que não apreendemos um cubo material completo, mas construímos sua identidade/ essência/ sentido por intencionar seus aspectos, também na obra de arte literária apreendemos aspectos e os compomos em uma totalidade emergente (sentido ou o que Ingarden também chama de polifonia harmônica) e, com isso, atualizamos e apreendemos o objeto real. ${ }^{27}$

No entanto, a noção de essência e sentido para Ingarden não compreendem nem uma vontade do autor ou "sentido original", nem algo que idealmente e atemporalmente irá permanecer e atravessar a obra do autor ao leitor. $\mathrm{O}$ autor e suas vontades somem no momento em que a elaboração da obra termina. O que importa foi o que ele construiu. Tudo a que temos acesso na obra de arte são construtos, artefatos. $\mathrm{O}$ sentido "original" é o núcleo construído de um objeto esquemático potencial, que será atualizado em significações contingentes e que jamais apreenderão a coisa completa absoluta ${ }^{28}$ (i.e., sentido original é um conjunto esquemático - incompleto - de instruções para construir um 
Hamlet ou para construir uma obra X). ${ }^{29}$ Deste modo, vale compreender a obra de arte literária em Ingarden como um artefato que operar, ou seja, que só tem vida a partir de sua operação/ execução. Qualquer ato de mover ou afetar o outro é a partir da configuração da obra, é efeito da recepção de um construto em funcionamento.

\section{CONCLUSÃo}

Fica, assim, estabelecido tanto o lugar central da noção de ação para obra de arte quanto seu caráter de construto, isto é, a obra de arte literária como um artefato que necessita de uma ação performativa para ser. Essa noção atravessa a produção do autor polonês, no entanto, ela se torna aparente apenas quando atentamos para sua proposta tomada como uma ontologia da obra de arte literária. É este foco que a filosofia da arte anglófona permite restabelecer, ampliando e atualizando, dessa forma, a obra do autor polonês. Justamente para o filósofo que pretende que a ontologia trate não apenas daquilo que é, mas também e, sobretudo, daquilo que pode ser. Nada mais adequado para o eterno devir da obra de arte literária.

\section{Notas}

1. "O valor artístico [...] é algo que surge na própria obra de arte e tem sua base existencial em si. O valor estético é algo que se manifesta somente no objeto estético e como um momento particular que determina a caráter do todo. A base do valor estético consiste em certa aglomeração de qualidades esteticamente valiosas, e elas, por sua vez, se calcam sobre certa aglomeração de propriedades que tornam possível sua emergência em um objeto. Tanto um quanto o outro tipo de valor pressupõe a existência de uma obra de arte (ou objeto estético) completa(o)". (INGARDEN, 1964, p. 205, grifos do autor).

2. Há uma diferença entre a nomenclatura de Ingarden (1964) e Mcfee (2011), já que o último afirma que não há ou não pode haver "propriedades estéticas" da obra de arte, mas somente "propriedades artísticas", devido ao fato de que qualquer propriedade do artístico leva em consideração a localização deste como tal e, por isso, todo valor derivado de uma obra de 
arte é um valor localizado como artístico. $\mathrm{O}$ que pode parecer contrário a Ingarden é, na realidade, bastante próximo de sua filosofia já que, para o filósofo polonês, não existe qualidade ou valor puramente subjetivo, e, sim, somente aquele fundado na obra de arte e em seu entorno.

3. Pode-se questionar se é possível pensar tais características como "neutras", entretanto, este problema foge ao escopo deste artigo.

4. "1. Não é nem uma parte nem um aspecto de nossas experiências empíricas ou estados mentais na relação com a obra de arte e, portanto, não pertence à categoria de prazer ou gozo.

2. Não é algo atribuído à obra em virtude de ser considerada um instrumento para despertar este ou aquele tipo de prazer.

3. Ela se mostra como uma característica específica da obra mesma.

4. Ela existe se e somente se as condições necessárias para a sua existência estão presentes nas qualidades da própria obra.

5. É de tal modo que sua presença faz com que a obra de arte participe de uma forma de ser inteiramente especial, distinta de todos os outros produtos culturais". (INGARDEN, 1964, p. 201).

5. "Neste contexto, para descobrir se um determinado aspecto de uma obra tem valor positivo ou negativo, não é suficiente examinar as características de valor desse aspecto isoladamente; é necessário estender o exame a toda à obra, uma vez que várias qualidades desse tipo podem, e às vezes devem, exercer influência mútua com relação as suas características de valor e é somente na unidade toda orgânica da obra (onde tanto suas características neutras, quanto significativas de valor são levadas em consideração) que sua forma final é exibida. Isto está de acordo com a declaração anterior de que a função real dos momentos artisticamente valiosos somente vêm à tona com base na apreciação da obra, o que não é possível enquanto nos limitarmos ao desfrute de uns e outros prazeres empíricos mediados por eles". (INGARDEN, 1964, p. 210).

6. "algo a ser detectado na obra mesma e não identificado com qualquer experiência subjetiva ou estado psicológico de admiração ou prazer". (INGARDEN, 1964, p. 210).

7. "Meus achados concordam com a visão que Husserl expressa em Lógica Formal e Transcendental, de que o significado das palavras, frases e 
unidades superiores de sentido são formações que surgem de operações subjetivas de consciência. Portanto, elas não são objetividades ideais no sentido em que Husserl as determinou em suas Investigações Lógicas. Mas enquanto Husserl mantém o termo 'ideal' na maioria das ocorrências de sua Lógica e somente algumas vezes acrescenta a palavra irreal em parênteses, eu abandonei completamente esse termo e procuro nitidamente contrapor essas formações a objetividades ideais no senso estrito. Essa é a primeira diferença essencial; todas as objetividades que Husserl previamente tinha como ideal - no sentido antigo - ele agora considera formações intencionais de um tipo particular, e, desta forma, ele consegue uma extensão universal do idealismo transcendental. Diferentemente, eu hoje ainda mantenho a rígida idealidade de diversas objetividades ideais (conceitos ideais, objetos individuais ideais, ideias e essências) e vejo nos conceitos ideais uma fundação ôntica das significações das palavras que as permitem ter uma identidade intersubjetiva e um modo de existência onticamente autônomo. Ao mesmo tempo, para Husserl a nova concepção de formações lógicas surge principalmente de investigações fenomenológicas e motivos idealista-transcendentais gerais, enquanto minhas observações são orientadas ontologicamente e procuram mostrar, nas próprias formações lógicas, uma série de estados das coisas que tornam existência ideal, no sentido estrito, impossível para eles, e simultaneamente indica sua origem ôntica em operações subjetivas". (INGARDEN, 1973a, p. lxxiv, grifo meu).

8. Como o autor recusa que a obra de arte seja um real/material, a tendência pode ser de pensar que ele resvalaria para o ideal, o que seria um engano, pois Ingarden recusa absolutamente que a obra seja um ideal. Este elemento nem mesmo aparece na obra.

9. Thomasson ressalta essa proximidade ao dizer que: "Ontology, in Ingarden's hands, thus bears close resemblance to the sorts of conceptual analysis that became common in analytic philosophy in roughly the same period" (THOMASSON, 2012, n. p.).

"A ontologia, nas mãos de Ingarden, tem assim uma grande semelhança com os tipos de análise conceitual que se tornaram comuns na filosofia analítica por volta do mesmo período". (THOMASSON, 2012, n. p.). 
10. Essa noção da linguagem como propulsora de ação e da possibilidade de afetar o público se deve, em parte, às leituras que Ingarden fez de Karl Bühler e sua Sprachtheorie (2011), sendo este um dos primeiros a propor a linguagem como ação.

11. Não se trata de eliminar a possibilidade proposicional da linguagem, mas, sim, de mudar o foco para ação e dizer, como Austin (1999), que o caráter proposicional - ou ato locucionário - é apenas mais uma possibilidade e parte do ato da linguagem.

12. "aquelas entidades que não são rigidamente e constantemente dependentes de qualquer entidade real e, portanto, não possuem uma localização espaciotemporal. Essa concepção é próxima ao entendimento mais comum do termo "abstrato" e torna concreta e abstracta categorias mutuamente exclusivas e exaustivas". (THOMASSON, 1999, p. 127).

13. "diferente dos abstracta dos platonistas, obras de música e literatura não existem de forma independente; elas apenas podem vir a existir a partir de formas de intencionalidade humana e, mesmo depois de criadas, elas não são independentes e eternas, mas dependem de alguma cópia ou performance, ou de qualquer meio para criar uma (seja através de uma partitura, gravação, memória ou qualquer combinação dessas) para sua contínua existência”. (THOMASSON, 2004, p. 90, grifo da autora).

14. De acordo com Margolis, e que pode ser constatado também pela leitura de Thomasson: "The advantage of Ingarden's informality lay in its openness to plural, non-converging interpretations and in its tolerance of the contingent, shifting historical conditions under which art is actually appreciated" (MARGOLIS, 1979, p. 114).

"A vantagem da informalidade de Ingarden reside em sua abertura a interpretações plurais não convergentes e sua tolerância às condições históricas contingentes e mutáveis a partir das quais a arte é efetivamente apreciada". (MARGOLIS, 1979, p. 114).

15. "Pois, como pinturas e esculturas, outros artefatos e objetos sociais concretos como mesas, carteiras de motorista e imóveis não são meramente idênticos à matéria que os constitui, já que estes (diferente da matéria) têm relações essenciais com estados de intencionalidade humana. Como obras de música e literatura, teorias, corporações e leis de estado parecem ser 
entidades culturais abstratas que são criadas em certo momento a partir de atividades humanas". (THOMASSON, 2004, p. 90).

16. "obras de arte são produtos de trabalho culturalmente informado diferentemente de objetos físicos. Assim visto, elas devem possuir propriedades que objetos físicos, qua objetos físicos, não possuem e não podem possuir". (MARGOLIS, 1977, p. 48).

17. Deve-se lembrar aqui que esse ato intencional ocorre a despeito de nossa vontade. É nosso modo de estar no mundo.

18. "uma habilidade representacional derivada de atos intencionais que conferem sentido a formações fonéticas (e tipográficas). Portanto, apesar de personagens ficcionais permanecerem mediatamente dependentes na intencionalidade, a imediata dependência de personagens de ficção em palavras e frases lhes dá uma relativa independência de qualquer ato de consciência particular". (THOMASSON, 1999, p. 22).

19. Uma versão resumida deste texto foi proferida pelo autor em um congresso em Paris em 1937, como também foi publicado como o capítulo de The Cognição of the Literary Work of Art (1973b). O texto utilizado no presente artigo é uma tradução a partir do livro Cognition em polonês enquanto que a versão inclusa na edição norte-americana do livro Cognition (1973b) foi traduzida a partir do alemão.

20. Originalmente lido em março de 1969, um ano antes de sua morte em 1970.

21. "O mundo material entra como um pano de fundo e se exibe na forma da fundação ontológica da obra de arte". (1975a, p. 260).

22. Aqui fica claro o elemento contextual cultural histórico na concretização da obra de arte na filosofia de Ingarden.

23. "Esse objeto, coisa, processo ou evento pode ser algo puramente físico, ou certo fato na vida e experiência de um observador, ou um motivo musical, um fragmento de melodia ou uma harmonia de sons, um contraste de cores, ou uma qualidade metafísica particular". (INGARDEN, 1975a, p. 263).

24. "o comportamento criativo de um artista cobre não só suas experiências produtivas, mas também certas ações físicas que adequadamente moldam uma coisa ou processo particular, para que ele possa atuar na função de uma base ontológica para uma pintura, uma escultura, um poema ou uma sonata”. (INGARDEN, 1975a, p. 260). 
25. Um modo de elucidar o fato de que o "ser Y" não depende somente da minha afecção (subjetiva) individual, seria pelo dinheiro de papel. Não importa se eu, como indivíduo, não acredito que aquele pedaço de papel tenha valor de troca em sociedade. Enquanto eu e outros ainda o utilizarmos e o reconhecermos para a prática de troca, ele terá valor. Trata-se de um elemento fundado por modos de agir e reconhecimentos e não por afecção subjetiva. Isso será explorado mais adiante.

26. "Ver algo como arte requer algo que o olho não pode descriminar" (1964, p. 580).

27. O que quer dizer que Ingarden aplica a noção de aspectos esquemáticos da fenomenologia no objeto artístico.

28. O objeto estético para Ingarden é uma formação de sentido pelo leitor, a partir do objeto esquemático. Tanto que Ingarden geralmente a descreve como emoções ou conceitos complexos como serenidade, sublimidade, profundidade, o que, em parte, denota uma distância de um sensível sendo meramente prazer ou outras sensações mais imediatas.

29. Tal se dá porque o modelo de Ingarden não tem mais "sentido" enquanto constatação de verdade de uma proposição representacional lógicosemântica. Assim, a própria noção de sentido para ele é a de uma execução sucedida.

THE LITERARY WORK AS ARTIFACT AND ACTION THROUGH ROMAN INGARDEN

\section{AbSTRACT}

In the present article I attempt to understand Roman Ingarden's concept of literary work from the viewpoint of artifactuality and performativity, that is, understand the work of art as an artifactualization and virtualization of reality through intentionality, which, in turn, configures sense/meaning as a mode of action or as an instruction for a performative act. To understand this, one must locate Ingarden's philosophy of art as distancing itself from a philosophical aesthetics, and in consonance, from the 60s onward, with Anglophone philosophy of art, above all its concerns with ontology and contextuality.

KEYWORDS: ontology, artifact, performance, Roman Ingarden. 


\section{RESUMEN}

Este artículo intenta comprender el concepto de obra literaria en los textos de Roman Ingarden a partir de las nociones de artefacto y performance, esto es, la obra de arte como una artificialización y virtualización de lo real según una intecionalidad que configura el sentido como un modo de actuar o como instrucción para la acción. Para ello, es necesário ubicar la filosofía del arte de Ingarden distanciada de una filosofía estética y que está en consonancia, a partir de los años 60 , con la filosofía del arte anglófona, sobre todo en lo concerniente a su foco ontológico y contextualista.

PALABRAS Clave: ontología, artefacto, performance, Roman Ingarden.

\section{REFERÊNCIAS}

AUSTIN, John L. How to do things with words. Cambridge: Harvard University, 1999.

BRAIDA, Celso R. Filosofia e linguagem. Florianópolis: Rocca Brayde, 2013. BÜHLER, Karl. Theory of Language: The representational function of language. Trad. Donald Fraser Goodwin; Achim Eschbach. Philadelphia: John Benjamins Publishing Company, 2011.

CARROLL, Noël. Beyond aesthetics: philosophical essays. New York: Cambridge University, 2003.

DANTO, Arthur. The Artworld. The Journal of Philosophy, v. 61, n. 19, p. 571584, 1964. Disponível em: <http://www.jstor.org/stable/2022937>. Acesso em: 12 maio 2014.

. The Transfiguration of the commonplace: a philosophy of art. Cambridge: Harvard University, 1981.

DICKIE, George. The Myth of the aesthetic attitude. American Philosophical Quarterly, v. 1, n. 1, p. 56-65, 1964. Disponível em: <http://www.jstor.org/ stable/20009119>. Acesso em: 15 jan. 2014.

FERREIRA, Debora Pazetto. Análise categorial da arte em Amie Thomasson. 2010. 144 f. Dissertação (Mestrado em Filosofia) - Programa de Pós-Graduação 
em Filosofia, Centro de Filosofia e Ciências Humanas, Universidade Federal de Santa Catarina, Florianópolis, 2010.

GREENBERG, Clement. Homemade esthetics: observations on art and taste. New York: Oxford University, 2000.

INGARDEN, Roman. A esthetic experience and aesthetic object. Philosophy and Phenomenological Research, v. 21, n. 3, p. 289-313, 1961. Disponível em: $<\mathrm{http}$ ://www.jstor.org/stable/2105148>. Acesso em: 12 set. 2014.

. Artistic and aesthetic values. British Journal of Aesthetics, v. 4, n. 3, p. 198-213, 1964. Disponível em: <http://bjaesthetics.oxfordjournals.org/ content/4/3/198.full.pdf + html $>$. Acesso em: 13 set. 2014.

. On the motives which led Husserl to transcendental idealism. Trad. Arnór Hannibalsson. Den Haag, Netherlands: Martinus Nijhoff, $1975 b$.

. Phenomenological aesthetics: an attempt at defining its range. The Journal of Aesthetics and Art Criticism, v. 33, n. 3, p. 257-269, 1975a. Disponível em: <http://www.jstor.org/stable/428352>. Acesso em: 30 ago. 2014.

. The Literary work of art. Trad. George G. Grabowicz. Evanston: Northwestern University, 1973a.

.The Cognition of the literary work of art. Tradução Ruth Ann Crowley, Kenneth R. Olson. Evanston: Northwestern University, 1973b.

KANT, Immanuel. Critique of judgment. Tradução Werner S. Pluhar. Indianapolis: Hackett Publishing, 1987.

MARGOLIS, Joseph. The Ontological peculiarity of works of art. The Journal of Aesthetics and Art Criticism, v. 36, n. 1, p. 45-50, 1977. Disponível em: $<\mathrm{http}: / / w w w . j s t o r . o r g /$ stable/430748>. Acesso em: 2 abr. 2014.

. Recent currents in aesthetics of relevance to contemporary visual artists. Leonardo, v. 12, n. 2, p. 111-119, 1979. Disponível em: <http://www. jstor.org/stable/1573833>. Acesso em: 2 abr. 2014.

MCFEE, Graham. Artistic Judgement: a framework for philosophical aesthetics. London: Springer, 2011.

MITSCHERLING, Jeff. Roman Ingarden's ontology and aesthetics. Quebec: University of Ottowa Press, 1997.

SCHILLER, Friedrich. Educação estética do homem. Tradução Roberto Schwarz; Márcio Suzuki. São Paulo: Iluminuras, 1995. 
SEARLE, John R. Speech acts: an essay in the philosophy of language. New York: Cambridge University Press, 1984.

. The Construction of social reality. New York: The Free Press, 1997.

SHAKESPEARE, William. Hamlet, Prince of Denmark. (The New Cambridge Shakespeare). Cambridge: Cambridge University Press, 2003.

SOKOLOWSKI, Robert. Introduction to phenomenology. New York: Cambridge University, 1999.

THOMASSON, Amie. Roman Ingarden. In: The Stanford encyclopedia of philosophy. Stanford: Metaphysics Research Lab/Center for the Study of Language and Information/Stanford University. 2012. (ed. Edward N. Zalta). Disponível em: <http://plato.stanford.edu/archives/fall2012/entries/ ingarden/>. Acesso em: 2 maio 2014.

1999.

. Fiction and metaphysics. New York: Cambridge University Press,

. The Ontology of art. In: KIVY, Peter. The Blackwell guide to aesthetics. Oxford: Blackwell Publishing, 2004. p. 78-92.

Submetido em 04 de abril de 2018

Aceito em 22 de agosto de 2018

Publicado em 11 de abril de 2019 